\title{
The arise of SARS-CoV-2 Delta variant in Cape Verde
}

\author{
Gisseila Andrea Ferreira Garcia ${ }^{a}$, Andrêa Jacqueline Fortes Ferrreira ${ }^{b}$, Mara Yone Soares Dias \\ Fernandes ${ }^{c}$

\begin{abstract}
${ }^{a}$ Faculty of Medicine, Federal University of Minas Gerais, Belo Horizonte, MG, Brazil. Scientific Department/CVDN, Mindelo, Cape Verde.

${ }^{b}$ Centre for Integration of Data and Knowledge for Health (CIDACS-Fiocruz/Bahia), Salvador, BA, Brazil. Scientific Department/CVDN, Mindelo, Cape Verde.
\end{abstract} \\ 'Faculty of Medicine, Federal University of Ceará, Fortaleza, CE, Brazil. Scientific Department/CVDN, Mindelo, Cape Verde.
}

ABSTRACT Since March 2020, we have been living in a pandemic caused by the SARS-CoV-2 virus, responsible for COVID-19 disease. The emergence of new variants and strains of SARS-CoV-2 virus, in particular the Delta variant in October 2020, sparked a new alert for the scientific community, given its high efficiency in replication and transmissibility, as well as its relationship to more serious symptoms, which contribute to the increase of hospitalization and mortality rates, particularly in African countries. In this case report, we explored the arrival of the Delta variant in Cape Verde, an African middle-income country, in August 2021, and analyzed its possible effects on increased notification of new cases and mortality rates in the country, as well as the health system's responsiveness to the new variant. This is particularly relevant given the country's lack of infrastructure for the screening and surveillance of new variants, which, therefore, influence the adoption of new mitigation and control measures for COVID-19 prevention, particularly in this period of flexibilization of the most COVID-19 restrictive measures (i.e. social distance), return of tourism and schools activities in the country.

KEYWORDS: COVID-19; Delta Variant; Africa

Accepted October 20, 2021 Published online November 19, 2021

Cite this article: Garcia et al. (2021) The arise of SARS-CoV-2 Delta variant in Cape Verde. Multidisciplinary Science Journal 3: e2021018, doi:10.29327/multiscience.2021018.

\section{Introduction}

The pandemic of COVID-19, declared by the World Health Organization (WHO) in March 2021, has brought a great challenge to many, if not all, countries in the world concerning health and epidemiological surveillance (Cucinotta and Vanelli 2020). COVID-19 is a disease caused by the new coronavirus, SARS-CoV-2, which has shown a high morbidity and mortality rate worldwide (Kang and Xu 2020). Due to its high transmissibility, the virus has undergone continuous mutations that trigger new strains and variants, SARS-CoV-2 B.1.617.2, the Delta variant, the most discussed currently (Vaidyanathan 2021).

The Delta Variant was first identified in October 2020 in India, making it the variant with the highest replication efficiency and transmissibility compared to the other variants before it, including B.1.617.1 (Kappa) and B.1.17 (Alpha) (Mlcochova et al 2021; Singh et al 2021). According to WHO data, the B.1.617 strain is divided into three subtypes: B.1.617.1 (Kappa), B. 1.617.2 (Delta), which was also recently designated as VOC, and B.1.617.3 (WHO 2021a). The Delta variant is approximately $50 \%$ more contagious than the Alpha variant and almost twice as contagious as the original Wuhan virus strain (Dagan et al 2021). The catastrophic spread of this variant has led to a second massive wave of 
positive cases in India and UK, and has spread to at least 92 countries in recent months (Rosa-Aquino 2021; Starr et al 2021).

In Africa, the Delta variant was first reported in countries that have close economic ties with India, such as those in East Africa (Callaway 2021; Obande et al 2021). Namibia, Zambia, and South Africa have been reporting the highest number of new cases, with the latter being the dominant African country affected by this new variant, as well as the country accounting for half of all cases in Africa until August 2021 (United Nations 2021b). Furthermore, according to United Nations (United Nations 2021a) data, the Delta variant was sequenced in 97\% of COVID-19 samples in Uganda and $79 \%$ of those samples in the Democratic Republic of Congo on the same date. It is also important to note that most of the cases identified on the African continent are related to young adults. For instance, $66 \%$ of the sequenced samples in Uganda belonged to individuals under the age of 45. According to the WHO (WHO 2021b), after the Delta variant arrived in Africa in January 2021 (Cheng et al 2021), it caused a more aggressive third wave in several countries, with increased transmissibility, severe disease, and an 80\% increase in COVID-19 mortality rate (United Nations 2021a; WHO 2021b). Moreover, studies point out that the lack of diagnostic capacity in many of these countries may lead to uncertainty in case reporting, as well as a greater burden on health systems compared to previous waves. In parallel, most African countries have limited access to vaccines, and some of them until now have vaccinated less than $5 \%$ of the eligible population (i.e.: 18 years or more). Therefore, the impact of the Delta variant could be devastating for African countries if more equitable vaccination policies were not taken into account (Callaway 2021).

In this context, with this case report, we aim to explore the arrival of the Delta variant in Cape Verde, an African country with 10 islands and approximately 500,000 people (Country 2021). The country notified the first case of COVID19 on March 19, 2020, and since then has been dealing with fluctuations in the number of cases and all the problems that this pandemic has also brought to other places in the world (Garcia et al 2021). On August 11, 2021 (Ministério de Saúde 2021), the country notified the first sequenced case of the Delta variant (Ministério de Saúde 2021). Given the lack of local infrastructure for screening and surveillance of new variants, we intend to analyze the effects of this new variant in Cape Verde on case notification and mortality rates, as well as its impact on the health system's ability to respond to this new variant.

\section{Delta Variant in Cape Verde}

According to the local government, the Delta variant has only been detected in Santiago, the island with the largest number of inhabitants in the country. Until now, Santiago was the island that also reported the highest proportion of notifications, hospitalizations and deaths due to COVID-19 in the whole country (Ministério de Saúde 2021). A major issue related to the announcement of Delta variant arrival in Cape Verde is the fact that these results were obtained from samples collected in May 2021, which means that the Delta variant was circulating in the country since or even before May (Ministério de Saúde 2021).

The lack of time observed between sample collection and announcement of the results was related to the fact that Cape Verde does not yet have neither laboratory equipment nor techniques for the identification and genetic sequencing of this and other COVID-19 variants (Ministério de Saúde 2021). All samples of suspect cases must be processed at the Pasteur Institute in Dakar (Senegal), which is 612 miles away from the Cape Verde islands. This brings a major challenge for local public health authorities since, without accurate surveillance of the variants circulating in the country, COVID-19 could be out of control, particularly in this period of flexibilization of restrictive relaxed control measures for COVID-19, and the increasing circulation of tourists, immigrants, and natives during the summer period. Also, studies point out that the Delta variant could be more dangerous among those who are unvaccinated, as well as those who have not completed vaccination schedules (Lopez Bernal et al 2021; Thangaraj et al 2021), as well as the association among this new variant with an increase of risk for hospital admission and death, even in countries with high vaccination coverage such as England (Mahase 2021; O'Dowd, 2021) and USA (Herlihy et al 2021).

Advances in vaccination are already having a positive impact on mortality caused by COVID-19 worldwide. Research shows that the Delta variant spreads rapidly among unvaccinated individuals, as $73 \%$ of the cases are seen in unvaccinated people and only $3.7 \%$ in people who have received both doses (Yeung 2021). Despite the start of vaccination in Cape Verde in March 2021, by September 19, 2021, only 30.8\% of the eligible population had received both doses of COVID-19 vaccine, although the average coverage of the first dose among adults was $75.5 \%$ in the whole 
country (Portal Covid 2021a). However, positive COVID-19 cases have been increasing in Cape Verde in the last weekends, mostly among unvaccinated individuals, as reported by the Minister of Health, which shows the importance of vaccination in COVID-19 control (Portal Covid 2021b)

\section{Other SARS-COV-2 variants and strains announced in the country}

Alongside the arrival of the Delta variant in Cape Verde, local authorities confirmed the Alpha variant as the most common variant circulating in the country. Also, they announced the circulation of a new variant in Santiago island - the Eta variant - which is considered a variant of interest by WHO, and 21 strains of SARS-CoV-2, most related to the B.1 variant (Expresso das Ilhas 2021). Public Health authorities also confirmed the detection of L.1 strain in the samples analyzed. L.1 strain was first detected in Canada, and this could be the first time that this strain was detected in an African country (O'Toole et al 2021).

\section{Recommendations}

Given the current scenario, it is mandatory to take new measures to mitigate the impact that the Delta variant might have on the Cape Verdean population, as well as rethink new strategies to control and/or prevent the spread of this new variant to the other islands of Cape Verde. Given that vaccination is the main strategy to prevent serious illness and death from COVID-19, the first measure would be to expand and accelerate the vaccination process in the country, as well as intensify mitigation measures since no single strategy alone can prevent transmission of SARS-CoV-2.

Thus, multiple interventions must be used simultaneously to reduce the spread of disease, such as consistent and correct use of masks, maximizing ventilation through both dilution and filtration of air in enclosed spaces, physical distancing, and avoiding physical crowds (Christie 2021). Moreover, it is also necessary that as countries begin to flexible pandemic control measures, the emergence of new variants, their impacts on transmissibility, uptake, and vaccination effectiveness should be monitored continuously (Sonabend et al 2021). In this sense, the impossibility of Cape Verdean authorities to perform local genomic surveillance of SARS-CoV-2 variants and strains highlighted the urgent need for strengthening the national health systems and the epidemiologic surveillance system that enable the equipment of national laboratories and the training of public health professionals.

Considering the summer period, and, therefore, the intensification of tourists and migrants in the national territory, as well as the return of schools and the upcoming presidential elections in October 2021, it is expected an increase in case notification and death due to COVID-19, particularly with the circulation of Delta variant, which could worsen the pandemic scenario in the country. Since the announcement of the Delta variant in Cape Verde, local authorities have accelerated the vaccination process, but this might not be sufficient since we have been observed in recent months, agglomerations during presidential election campaigns, intense movement of people among the islands, and an absence of mass testing in the country, as well as surveillance of new cases and their contacts.

\section{Final Considerations}

The arrival of SARS-CoV-2 Delta variant on Cape Verde brings new challenges for public health, and also arise concerns regarding flexible measures adopted by local authorities, particularly, due to the scarcity of resources to perform a massive test and genomic surveillance for new variants and strains, which could compromise the control of COVI-19 in the whole country. As Cape Verde, other African countries need to improve their health and epidemiologic surveillance capability to screen and better control COVID-19 pandemic and also prepare for future epidemics. Public Health institutions must be capable of acting to improve their health security control, and measures should be taken so the countries can manufacture their own vaccines and improve their ability to prevent, diagnose and treat the patients.

\section{Conflict of Interest}

The authors declare no conflict of interest.

\section{Funding}


The author Gisseila Andrea Ferreira Garcia declares that she is receiving a doctoral scholarship from the National Council for Scientific and Technological Development (CNPQ) during the execution of this research.

\section{References}

Brown CM, Vostok J, Johnson H, Burns M, Gharpure R, Sami S, Sabo RT, Hall N, Foreman A, Schubert PL, Gallagher GR, Fink T, Madoff LC, Gabriel SB, Maclnnis B, Park DJ, Siddle KJ, Harik V, Arvidson D, Laney AS (2021) Outbreak of SARS-CoV-2 Infections, Including COVID-19 Vaccine Breakthrough Infections, Associated with Large Public Gatherings-Barnstable County, Massachusetts, July 2021. Morbidity and Mortality Weekly Report. DOI: 10.15585/mmwr.mm7031e2

Callaway E (2021) Delta coronavirus variant: Scientists brace for impact. DOI: 10.1038/d41586-021-01696-3

Cheng C, Wang L, Lyu Z, Peng B, Li Y, Kong D, Zuo L, Zhang X, Yang C, Liu W, Wan J, Tang Y, He J, Wen Y, Xu S, Wu W, Chen Y, Liu G, Xia J, Feng T (2021) Four COVID-19 Cases of New Variant B.1.351 First Emerging in South Africa in Chinese Passengers on Same FlightShenzhen, China, January 2021. China CDC Weekly. DOI: 10.46234/ccdcw2021.049

Christie A (2021) Guidance for Implementing COVID-19 Prevention Strategies in the Context of Varying Community Transmission Levels and Vaccination Coverage. MMWR. Morbidity and Mortality Weekly Report. DOI: 10.15585/mmwr.mm7030e2

Country M (2021) População de Cabo Verde 2021. Feed Navigator. Available in: https://countrymeters.info/pt/Cape_Verde. Accessed on: 22 September, 2021.

Cucinotta D, Vanelli M (2020) WHO Declares COVID-19 a Pandemic. Acta Bio-Medica: Atenei Parmensis. DOI: 10.23750/abm.v91i1.9397

Dagan N, Barda N, Kepten E, Miron O, Perchik S, Katz MA, Hernán MA, Lipsitch M, Reis B, Balicer RD (2021) BNT162b2 mRNA Covid19 Vaccine in a Nationwide Mass Vaccination Setting. New England Journal of Medicine. DOI: 10.1056/NEJMoa2101765

Expresso das Ilhas (2021) Detectadas três variantes e mais de 20 linhagens de SARS-CoV-2 no país. Expresso das Ilhas. Feed Navigator. Available in: https://ilhas.li/aJvX. Accessed on: 1 Outuber, 2021.

Garcia GAF, Tavares V, Moreno MJC, Martins DSMVC, Varela CFSA, Fernandes MYSD, Ferreira AJF (2021) Novo coronavírus SARSCoV-2 em Cabo Verde: Análise situacional após um ano de notificação do 10 caso. Multidisciplinary Reviews. DOI: 10.29327/multi.2021019

Herlihy R, Bamberg W, Burakoff A, Alden N, Severson R, Bush E, Kawasaki B, Berger B, Austin E, Shea M, Gabrieloff E, Matzinger S, Burdorf A, Nichols J, Goode K, Cilwick A, Stacy C, Staples E, Stringer G (2021) Rapid Increase in Circulation of the SARS-CoV-2 B.1.617.2 (Delta) Variant-Mesa County, Colorado, April-June 2021. MMWR. Morbidity and Mortality Weekly Report. DOI: 10.15585/mmwr.mm7032e2

Kang Y, Xu S (2020) Comprehensive overview of COVID-19 based on current evidence. Dermatologic Therapy. DOI: 10.1111/dth.13525

L'Institut Pasteur De Dakar (2021) Institut Pasteur de Dakar | Lbm, Lsahe, Vaccination, Fièvre Jaune, Recherche et Santé publique. Feed Navigator. Available in: https://www.pasteur.sn/fr. Accessed on: 28 September, 2021.

Lopez BJ, Andrews N, Gower C, Gallagher E, Simmons R, Thelwall S, Stowe J, Tessier E, Groves N, Dabrera G, Myers R, Campbell CNJ, Amirthalingam G, Edmunds M, Zambon M, Brown KE, Hopkins S, Chand M, Ramsay M (2021) Effectiveness of Covid-19 Vaccines against the B.1.617.2 (Delta) Variant. New England Journal of Medicine 385:585-94 .

Mahase E (2021) Delta variant: What is happening with transmission, hospital admissions, and restrictions? BMJ. DOI: 10.1136/bmj.n1513

Ministério de Saúde (2021) Ministério da Saúde de Cabo Verde. Feed Navigator. Available in: https://nenp.facebook.com/ministeriodasaude.cv/posts/2891190484478705. Accessed on: 28 Set. 2021.

Ministério de Saúde (2021) Variante Delta em Cabo Verde - COVID 19. Feed Navigator. Available in: https://covid19.cv/variante-deltaem-cabo-verde/. Accessed on: 14 September, 2021.

Mlcochova P, Kemp S, Dhar MS, Papa G, Meng B, Ferreira IATM, Datir R, Collier DA, Albecka A, Singh S, Pandey R, Brown J, Zhou J, Goonawardane N, Mishra S, Whittaker C, Mellan T, Marwal R, Datta M, Gupta RK (2021) SARS-CoV-2 B.1.617.2 Delta variant replication and immune evasion. Nature. DOI: https://doi.org/10.1038/s41586-021-03944-y

Obande GA, Bagudo Al, Mohamad S, Deris ZZ, Harun A, Yean CY, Aziah I, Banga S (2021) Current State of COVID-19 Pandemic in Africa: Lessons for Today and the Future. International Journal of Environmental Research and Public Health. DOI: https://doi.org/10.3390/ijerph18199968

O'Dowd A (2021) Covid-19: Cases of delta variant rise by 79\%, but rate of growth slows. BMJ (Clinical Research Ed.). DOI: doi: 10.1136/bmj.n1596

Portal Covid CV (2021a) Boletim de Vacinação - COVID 19. Feed Navigator. Available in: https://covid19.cv/boletim-de-vacinacao/. Accessed on: 28 September, 2021. 
Portal Covid CV (2021b). COVID 19 - Corona Virus. Feed Navigator. Available in: https://covid19.cv/. Accessed on: 28 September, 2021.

Rosa-Aquino CD, Paola A (202) What We Know About the Dangerous Delta Variant. Feed Navigator. Available in: https://nymag.com/intelligencer/article/covid-b-1-617-2-delta-variant-what-we-know.html. Accessed on: 4 September, 2021.

Singh J, Rahman SA, Ehtesham NZ, Hira S, Hasnain SE (2021) SARS-CoV-2 variants of concern are emerging in India. Nature Medicine. DOI: 10.1038/s41591-021-01397-4.

Starr TN, Greaney AJ, Addetia A, Hannon WW, Choudhary MC, Dingens AS, Li J Z, Bloom JD (2021) Prospective mapping of viral mutations that escape antibodies used to treat COVID-19. Science (New York, N.Y.). DOI: 10.1126/science.abf9302

Thangaraj JWV, Yadav P, Kumar CG, Shete A, Nyayanit DA, Rani DS, Kumar A, Kumar MS, Sabarinathan R, Kumar VS, Jagadeesan M, Murhekar M (2021) Predominance of delta variant among the COVID-19 vaccinated and unvaccinated individuals, India, May 2021. Journal of Infection. DOI: 10.1016/j.jinf.2021.08.006

The Lancet (2021) COVID-19 in Africa: A lesson in solidarity. Lancet. DOI: 10.1016/S0140-6736(21)01610-X

United Nations (2021a). Delta variant drives Africa COVID threat to 'whole new level': WHO warns; 'dominant' in Europe by August. UN News. Feed Navigator. Available in: https://news.un.org/en/story/2021/07/1095152. Accessed on: 7 September, 2021.

United Nations (2021b). Africa faces 470 million COVID-19 vaccine shortfall this year. UN News. Feed Navigator. Available in: https://news.un.org/en/story/2021/09/1100102. Accessed on: 7 September 2021.

Vaidyanathan G (2021) Coronavirus variants are spreading in India - What scientists know so far. Nature. DOI: 10.1038/d41586-02101274-7

Wall EC, Wu M, Harvey R, Kelly G, Warchal S, Sawyer C, Daniels R, Hobson P, Hatipoglu E, Ngai Y, Hussain S, Nicod J, Goldstone R, Ambrose K, Hindmarsh S, Beale R, Riddell A, Gamblin S, Howell M, Bauer DL (2021) Neutralising antibody activity against SARS-CoV2 VOCs B.1.617.2 and B.1.351 by BNT162b2 vaccination. The Lancet 397:2331-2333.

O’Toole Á, Scher E, Underwood A, Jackson B, Hill V, McCrone JT, Colquhoun R, Ruis C, Abu-Dahab K, Taylor B, Yeats C, Du Plessis L, Maloney D, Medd N, Attwood SW, Aanensen DM, Holmes EC, Pybus OG, Rambaut A (2021) Assignment of Epidemiological Lineages in an Emerging Pandemic Using the Pangolin Tool. Virus Evolution. DOI: https://doi.org/10.1093/ve/veab064.

WHO. (2021). WHO | Tracking SARS-CoV-2 variants. Feed Navigator. Available in: https://www.who.int/en/activities/tracking-SARSCoV-2-variants/. Accessed on: 2 October, 2021.

WHO (2021b) WHO I Regional Office for Africa. WHO | Regional Office for Africa. Feed Navigator. Available in: https://www.afro.who.int/search/node?keys=Delta+Variant. Accessed on: 10 September, 2021.

Yeung J (2021) Delta Plus: What we know about the coronavirus variant-CNN. Feed Navigator. Available in: https://edition.cnn.com/2021/06/25/health/delta-plus-variant-explainer-intl-hnk-scn/index.html. Accessed on: 10 Set. 2021. 